\title{
Exploring the perceptions of male nursing students enrolled in an accelerated baccalaureate degree nursing program
}

\author{
Brian T. Conner *, Berry S. Anderson, Robin Matutina \\ Medical University of South Carolina, United States
}

Received: January 25,2016

DOI: $10.5430 /$ jnep.v6n8p30

\author{
Accepted: February 23, 2016 \\ Online Published: March 22, 2016 \\ URL: http://dx.doi.org/10.5430/jnep.v6n8p30
}

\begin{abstract}
Objective: To gain understanding about the factors that drew men to an accelerated baccalaureate degree nursing program, the challenges they faced, and the support they need to complete the program.

Methods: This qualitative descriptive study explored the perceptions of male nursing students enrolled in an accelerated baccalaureate degree nursing program. The study design used semi-structured questions in a focus group format comprised of a sample of male nursing students currently enrolled in the ABSN program of a southeastern academic health sciences center. Relatively few studies have examined male nursing students, and those enrolled in a non-traditional program typically have unique circumstances. The significance of this study to nursing science is that the results will add to the growing body of knowledge regarding the recruitment and retention of males into nursing schools.

Results: Following data analysis, four themes emerged from the participant responses related to sacrifice, knowledge gain, organization for survival, and opportunities for men in nursing.

Conclusions: The results of this study highlight the attraction of accelerated BSN programs since many men opt for nursing as a second career choice. Results of this study may be used to improve recruitment and retention of male nursing students.
\end{abstract}

Key Words: Male nursing students, Men in nursing, Nursing education, Qualitative research

\section{INTRODUCTION}

Historically, females have dominated the nursing profession. Current estimates are that males comprise less than $10 \%$ of all registered nurses and nursing students in the United States, and the same is true for Canada. ${ }^{[1]}$ On the other hand, females comprise nearly $50 \%$ of all medical school enrollees, a field previously dominated by men. ${ }^{[2]}$ Further, women are increasingly moving into other more lucrative professional careers, thereby reducing the nursing workforce pool. Estimates are that the nursing shortage will continue to grow as more baby-boomer nurses move toward retirement. ${ }^{[3]}$ The
U. S. Bureau of Labor Statistics estimates approximately 550,000 nurses will retire by 2022 , while another 575,000 new nursing jobs will be created. ${ }^{[4]}$ Meanwhile, attrition rates among male nursing students exceed those of female students. ${ }^{[2]}$ Thus, the problem is how to improve recruitment and retention of male nursing students in order to increase the number of male nurses in the workforce.

A paucity of studies have been conducted on why men choose to enroll in nursing schools, the challenges they face as nursing students, and why they may choose to leave rather than

*Correspondence: Brian T. Conner; Email: connerb@musc.edu; Address: Medical University of South Carolina, United States. 
graduate. One recent literature review identified attrition, role strain, and isolation among a variety of challenges men face in nursing. ${ }^{[2]}$ They also discussed challenges such as sexual stereotyping, sexual differences in expressions of caring, and suspicions surrounding intimate touch. In truth, nursing has always been perceived as "women's work". Yet, male nurses have established strong contributions to areas such as critical care, emergency care, and mental health. ${ }^{[5]}$

Meadus and Twomey ${ }^{[3]}$ found that job security, job availability, career opportunities, role models, and the desire to help others were common motivators for men to choose to enroll in nursing schools. They further discussed retention issues such as male students' abilities to overcome educational stressors, embrace the idea of wide-open career choices, and enjoy the support of family, friends, classmates, and faculty as reasons for continuing through graduation.

A qualitative study of associate degree nursing students conducted by Ierardi, Fitzgerald, and Holland ${ }^{[6]}$ described that male nursing students wanted to care for others and found nursing education challenging, interesting, and satisfying. The study also found that men were often mistaken as physicians, and they often felt that nurses were referred to in feminine terms. These cultural stereotypes perpetuate the notion that nursing is "women's work".

Ellis, Meeker, and Hyde ${ }^{[7]}$ conducted a qualitative study of the educational experiences among male BSN students in one program. The study participants overwhelmingly highlighted career choices as a motivator for continuing in the programs. However, they also identified the unanticipated difficulties with the study of nursing. They did not realize the importance and intricacies associated with the necessary skills of professional nursing.

One area yet to be explored is that of male nursing students enrolled in accelerated baccalaureate of science in nursing degree programs (ABSN). These students typically have a collegiate degree in another field or, at a minimum, they have the necessary prerequisite courses for the ABSN program. For many, nursing will be a second career. Thus, the aim of this inquiry is to gain understanding about the factors that drew men to the ABSN program, the challenges they faced, and the support they need to complete the program. The significance of this study to nursing science is that the results will add to the growing body of knowledge regarding the recruitment and retention of males into nursing schools.

\section{MeTHODS}

This qualitative descriptive study design used focus groups comprised of a sample of male nursing students currently enrolled in the ABSN program of a southeastern academic health sciences center. The purpose of using focus groups is based on the concept that group interactions may yield responses and build insights that might not occur during oneon-one interviews. ${ }^{[8]}$ The total enrollment of male nursing students at the time of the study was 34 (18\% of all enrolled students), and 18 students (53\%) agreed to participate in the focus group interviews. The methodology for this qualitative study is based on the Colaizzi process for phenomenological data analysis. ${ }^{[9]}$ Phenomenology is a method to explore lived experiences of participants. The aim of this inquiry was to gain understanding about the factors that drew the men to the program, the challenges they faced, and the support they need to complete the program, then develop a description of the phenomena.

\subsection{Research question}

What are the perceptions of male nursing students currently enrolled in an accelerated baccalaureate nursing program?

\subsection{Ethical considerations}

The institutional review board gave approval prior to beginning the study. Male students enrolled in the ABSN program were recruited via an email invitation to participate; however, they were informed that their participation would be strictly voluntary and the choice to participate or not would in no way affect their course work, grades, or progress in the curriculum. A male faculty member who did not teach in the ABSN program lead the focus groups. Informed consent was obtained and participants were assured of anonymity and protection of their responses to the semi-structured questions (see Table 1). An audio recorder was used to record all respones but participants were not identified in any reporting of the results and none of the specific responses are attributed to any individual.

Table 1. Focus group questions

\begin{tabular}{|c|}
\hline $\begin{array}{l}\text { 1. Why did you choose to enroll in an accelerated baccalaureate nursing } \\
\text { program? } \\
\text { a. What lifestyle changes did you make in order to begin the program? }\end{array}$ \\
\hline $\begin{array}{l}\text { 2. Why did you choose to enroll in an accelerated baccalaureate nursing } \\
\text { program? }\end{array}$ \\
\hline a. What lifestyle changes did you make in order to begin the program? \\
\hline $\begin{array}{l}\text { 3. How has your experience of the program been for you? } \\
\text { a. What are some of the challenges you have faced within the program? } \\
\text { b. How have you overcome them? }\end{array}$ \\
\hline $\begin{array}{l}\text { 4. Have you ever considered leaving the program? } \\
\text { a. If so, why did you remain in the program? } \\
\text { b. What would you do differently if you could start over? }\end{array}$ \\
\hline $\begin{array}{l}\text { 5. Tell me what suggestions or recommendations you have for improving } \\
\text { the program in order to recruit and retain male nursing students. }\end{array}$ \\
\hline
\end{tabular}




\subsection{Data collection and analysis}

The responses from all focus group sessions were analyzed using a thematic approach to develop relevant categories of participants' reflections of their experiences. The data was then synthesized to determine several primary themes. The original voice recordings were deleted from the digital recorder after verifying the transcripts. Confidential study material wa kept securely in a locked cabinet with access only available to the primary investigator. No personal identifiers were used in the transcripts to ensure privacy and anonymity of the participants. The transcribed data were entered into QSR NVivo 10 for analysis and a step-by-step coding process was used to develop categories and themes. ${ }^{[9]}$ First, open coding was used to divide data into segments, or comprehensible stand-alone sentences and phrases. ${ }^{[10]}$ Significant statements were extracted and meanings formulated; then, comparative methods were used to merge concepts into initial categories. ${ }^{[9]}$ Next, category reduction was conducted through linkage of categories. And finally, selective coding was used to identify main themes. ${ }^{[1]}$

\section{Results}

Following data analysis, four themes emerged from the participant responses:

- Willing to make sacrifices for 16 months

- Wish I knew then what I know now

- Organization is the key to survival

- Many opportunities for men in nursing

The first theme identified was related to the reasons the men chose to enroll in the ABSN program. Nearly every participant agreed that the primary draw of the program was the relatively brief time frame from admission to graduation. The curriculum spans four consecutive semesters ranging from either fall-spring-summer-fall, or spring-summer-fall-spring. Thus, the program can be completed in 16 months. Since all of the students enrolled in this ABSN program have completed the general education prerequisites and most already have a baccalaureate degree, the accelerated nature of the program was clearly the most important factor in the decision process. The following participant comments illustrate the theme:

- The 16-month program was much faster than the associate program that I had looked at and the other bachelor program that I looked at.

- I am 40 years old, and I chose to do it because I wanted to have a career change. It was the fastest way for me to get from point A to point B to pursue what I wanted to pursue professionally.
- I was finishing up another degree at another university. I could've stayed another two years, or made the transition for 16 months here. I think it's the same principal, just fast track it.

The second identified theme is summarized as "wish I knew then what I know now" and is related to the challenges the participants have faced during the program. A majority of the men spoke about the intensity and volume of content to learn in each course. Many said they did not anticipate nursing school to be as complex and demanding as it is, and they were not at all prepared to answer the NCLEX style questions. This agrees with previous findings that men found nursing school more difficult than expected. ${ }^{[7]}$ One of the common statements was "I didn't realize I would not just be able to memorize content and that I would have to change my study habits entirely." Several of the students said they had thought about leaving the program but had enough support to remain. Two statements describe what the participants thought would help future male students:

- When I came in, my plan was to do it all on my own. Come to school, go home, study, do what I need to do. I quickly figured out that the class as a whole, the majority of the class was communicating on Facebook and doing things together outside of class to learn. I feel like the curriculum is geared a lot towards that, especially with group projects. I would totally recommend that men not try to go it alone from the beginning.

- If I had one thing to tell somebody coming in, is trying to do it on your own is probably not the way to do it because I feel like you're going to have to be more involved. People share information because it's difficult to find a lot of things in Moodle (electronic learning management system), and if you're not in that loop or that channel of communication, you're at a disadvantage.

Another emerging theme as a result of responses to a question about remaining in the program was related to organization being the key to survival. Nearly all of the participants agreed that the amount of reading and studying for quizzes and exams, preparation for clinical experiences, clinical paperwork, and group project work was overwhelming. Failure to remain organized, they said, often meant missed assignments or deadlines, or cramming at the last minute for a test. Several participants said they thought about leaving the program during the first two semesters because they had difficulty keeping up with all the work:

- First and second semesters, I spent more time trying to figure out what I needed to do, when I needed to do it 
by, what I needed to-what PowerPoints or what handouts I needed to bring to class. I spent more time doing that than actually studying. I feel like the amount of time that I put into that would've been much better spent studying.

- I think this program could use a little bit of fresh ideas, and be like okay, we're not in the 1970's anymore. We were writing these-first semester, you're doing 1000 's of med cards, and you were doing this in the 70s. Then, we had tons of paper work to get ready for clinical, care plans to write, all this stuff that took so much time that we didn't have time to study.

The final theme emerged in response to the question regarding recruitment and retention of men in nursing. Almost all of the participants stated that the program was definitely worthwhile and they were excited to begin their nursing careers. In terms of recruiting men for the ABSN program, the participants said that the emphasis should be placed on the vast array of opportunities available. Several participants commented that they had considered other health professions before beginning the ABSN program but felt that nursing offered so many more job opportunities:

- As soon as I started nursing school, I knew I wanted to get into some kind of critical care. Then, I met a flight nurse and I thought, wow that would be cool. Then, I met a nurse anesthetist and I thought, this is crazy, there are so many options.

- I think it is so important to get the word out to young guys that nursing is not just a sissy thing and that there are a lot of really cool jobs for men.

\section{Discussion}

This study explored the perceptions of a unique population of male nursing students who were enrolled in a non-traditional baccalaureate degree program. Overall, these men either already held a post-secondary academic degree, or they had the necessary amount of collegiate credits and pre-requisite courses to be admitted to the ABSN program. For many of the study participants, nursing represented a second career. Some were in business, some were in the military, and some were pursuing other health care related careers such as physical therapy.

The specific aim of the study was to explore the reasons these men chose to pursue a nursing degree, the challenges they faced once enmeshed in the program, and the support needed and received to remain in the program. Without doubt, the primary factor in their decisions to apply to the ABSN program was the time factor of 16 months. The curriculum of the program and the four consecutive semesters without a summer break were the most appealing aspects for these men.

Unfortunately, once entrenched in the curriculum the participants clearly described surprise that the program was much more difficult than expected. Many of the men had experience as emergency medical technicians, patient care technicians, or as medics in the military and, as such, believed the course work would be fairly easy. To that end, a majority of the men described trying to get through the courses without collaborating or seeking help from others. While social isolation has been identified as a barrier for men in nursing, ${ }^{[11-13]}$ little evidence is available to demonstrate that male nursing students isolate themselves.

An interesting revelation in this study involved the theme that the participants identified organization as the key to survival in the ABSN program. Many of the men described having difficulty in figuring out what to do and when to do it in order to complete assignments. Some of the participants described the amount of required paperwork as burdensome and seemingly unnecessary. Since this was a study of male nursing students, no data is available on the perceptions of female students enrolled in this ABSN program. However, anecdotal evidence suggests that women have less difficulty with organizational skills.

Finally, in spite of some of the unexpected challenges, nearly all of the participants agreed that enrolling in the ABSN program was worth the efforts due to the wide variety of opportunities available in the nursing profession. The participants agreed that recruitment and retention of male nursing students are both important elements toward increasing the number of men in nursing.

\subsection{Compare and contrast with the literature review}

Comparing and contrasting the study findings with the literature review, one finds many comparisons. For example, MacWilliams, Schmidt, and Bleich ${ }^{[2]}$ and Meadus and Twomey ${ }^{[3]}$ identified attrition or retention as one challenge. Meadus and Twomey ${ }^{[3]}$ mentioned support of family, friends, classmates, and faculty as reasons for continuing through graduation. Interestingly, our study combined these two themes as several students thought about leaving the program but found enough support to remain, specifically through classmates. For example, classmates supported one another through social networking websites, group projects, and sharing information. Furthermore, study participants advised future male ABSN students to identify classmate support early on and warned future students against trying to "go it alone".

MacWilliams, Schmidt, and Bleich ${ }^{[2]}$ and Ierardi, Fitzgerald, 
and Holland ${ }^{[6]}$ identified themes of sexual stereotyping and nursing as feminine "women's work". There was a comparison with our study participants as one study participant mentioned nursing being described as "sissy", but followed with the solution of the vast career opportunities also mentioned in the literature. ${ }^{[3,5,7]}$ Specifically, our study participants were interested in critical care, flight nursing, and nursing anesthesia which parallels male nursing students' preference for critical care, emergency care, and mental health nursing. ${ }^{[5]}$ Other students were older and attracted to the idea of a career change.

Ierardi, Fitzgerald, and Holland ${ }^{[6]}$ and Ellis, Meeker, and Hyde $^{[7]}$ identified nursing education as challenging and an unanticipated difficulty. Our study participants agreed, describing nursing school as complex and demanding and advised future male ABSN students that organization is key.

Contrasts or new findings not mentioned in the literature include the desirability of the fast track program. So in essence, three of the four study themes compared with the literature: (1) "Wish I knew then what I know now," (2) "Organization is key to survival," and (3) "Many opportunities for men in nursing." Whereas one theme: "Willing to make sacrifices for 16 months" arose as a new theme that may be a viable recruitment and retention tool as well as an instrument to correct misperceptions.

\subsection{Best Strategies for males in this program}

The best educational practices that evolved from this program include learning from the themes that appeared and compare with the literature: (1) Wish I knew then what I know now, (2) Organization is the key to survival, and (3) Many opportunities for men in nursing. An important educational practice may be to initiate a male nursing student mentorship program with mentors teaching new male ABSN students about survival skills including the importance of organization as well as seeking support from classmates. Another educational opportunity exists with teaching new male ABSN students about the specialties of nursing such as critical care, emergency care, flight nursing, and nursing anesthesia. Furthermore, new male ABSN students may be offered the opportunity to shadow nurses in these areas of expertise, ideally male nurses.

\subsection{Recruitment and retention}

This study and literature review revealed opportunities to improve recruitment and retention. For example recruitment materials may depict male nurses in the desirable specialties of critical care, emergency care, flight nursing, and nursing anesthesia. Recruitment materials may describe the male ABSN student mentorship program as well as the male nurse shadowing program. Recruitment materials may better prepare future male ABSN students for the rigor of the program with quotes from male ABSN students describing the program as intense, but rewarding and qualifying themselves as already holding bachelor degrees, in an effort to prepare incoming male ABSN students for the demands they are about to face to reduce the surprise factor.

\subsection{Research recommendations}

Research recommendations may include studying perceptions of male ABSN students after the following recommendations have been implemented: (1) an early male mentorship program, (2) an early male nurse shadowing program, and (3) recruitment materials preparing future male ABSN students for the rigor of the program. Other research recommendations include comparing and contrasting female ABSN students' perceptions as well as comparing gender specific perceptions in the array of nursing programs: diploma, associate, traditional BSN, and ABSN. Further study may include delving deeper into generational perceptions as well as second career students' perceptions.

\subsection{Study limitations}

This study was limited by the small sample of male participants enrolled in one academic health sciences university in the southeast. Additionally, there was little racial or ethnic diversity among the participants. The lack of comparison to the experiences of the women enrolled in this ABSN program is also an evident limitation and resulted in some speculation. A comparison to the perceptions of students enrolled in a traditional BSN program would be useful.

\subsection{Recommendations}

Future research on recruitment and retention issues related to men in nursing would be beneficial to the profession. Recommendations for future studies include:

- A comparison of male nursing student perceptions from other BSN programs and from other regions of the country.

- A comparison of the perceptions of male and female nursing students from a variety of BSN programs.

- A study of the perceptions of male nursing students enrolled in graduate nursing education.

- A longitudinal study exploring the perceptions of men in nursing following entry into the profession.

\section{Conclusion}

The looming shortage of registered nurses combined with the fact that many women are choosing a variety of other careers increases the importance and urgency of recruiting 
and retaining men in nursing. The results of this study highlight the attraction of accelerated BSN programs since many men opt for nursing as a second career choice. Additionally, four themes emerged: (1) Willing to make sacrifices for 16 months, (2) Wish I knew then what I know now, (3) Organization is the key to survival, and, (4) Many opportunities for men in nursing. Three of the themes correlate with the literature, whereas the draw of the expedited program emerged as a novel theme to aid with recruitment and retention into nursing, possibly addressing the nursing shortage. The study also highlighted a misperception that continues to exist in nursing, that nursing is a feminine profession. Another misperception that came to light was the unawareness of the rigor of nursing education. A third misperception was that nursing education may be approached independently, without support.

The students themselves revealed strategies to assist future male ABSN students. By pairing new ABSN students with male ABSN mentors, the "Wish I knew then what I know now" and "Organization is the key to survival" themes would be addressed. Experienced ABSN mentors would stress the importance of organization and finding support with classmates. By allowing new ABSN students to shadow male nurses who practice in critical care, emergency care, flight nursing, and nursing anesthesia, desirable areas of practice would be revealed to male ABSN students early in the program providing motivation and incentive.

\section{ACKNOWLEDGEMENTS}

This study was partially funded by a small grant from the Gamma Omicron Chapter of Sigma theta Tau International.

\section{CONFLiCtS OF InTEREST Disclosure}

The authors declare that there is no conflict of interest.

\section{REFERENCES}

[1] Dyck JM, Oliffe J, Phinney A, et al. Nursing instructors' and male nursing students' perceptions of undergraduate, classroom nursing education. Nurse Educ Today. 2008 Aug; 29: 649-653. http://dx.doi.org/10.1016/j.nedt.2009.02.003

[2] MacWilliam BR, Schmidt B, Blezgeraldich MR. Men in nursing. Am J Nurs. 2013 Jan; 113(1): 38-44.

[3] Meadus RJ, Twomey JC. Men student nurses: The nursing education experience. Nurs Forum. 2011 Oct-Dec; 46(4): 269-279. http://dx.doi.org/10.1111/j.1744-6198.2011.00239.x

[4] Robeznieks A. Looming nursing shortage fueled by fewer faculty, training sites. Mod Healthc. 2015 Jan; 45(4): 9.

[5] Abushaikha L, Mahadeen A, Abdelkader R, et al. Academic challenges and positive aspects: Perceptions of male nursing students. Int Nurs Rev. 2014 Jun; 61(2): 263-269. http://dx . doi .org/10.11 $11 /$ inr. 12098

[6] Ierardi JA, Fitzgerald DA, Holland DT. Exploring male students educational experiences in an associate degree nursing program. J Nurs Educ. 2010 Apr; 49(4): 215-218. http://dx.doi.org/10.3928 /01484834-20091217-04
[7] Ellis DM, Meeker BJ, Hyde BL. Exploring men's perceived educational experiences in a baccalaureate program. J Nurs Educ. 2006 Dec; 45(12): 523-527. PMid:17190367.

[8] Slade SC, Molloy E, Keating JL. 'Listen to me, tell me': A qualitative study of partnership in care for people with non-specific chronic low back pain. Clin Rehabil. 2009 Mar; 23(3): 270-280. http://dx.doi.org/10.1177/0269215508100468

[9] Shosha GA. Employment of Colaizzi's strategy in descriptive phenomenology: A reflection of a researcher. Eur Sci J. 2012 Nov; 8(27): 31-43.

[10] Mclafferty I, Morrison F. Attitudes towards hospitalized older adults. J Adv Nurs. 2004 Aug; 47(4): 446-453. PMid:15271164. http: //dx.doi.org/10.1111/j.1365-2648.2004.03122.x

[11] Strauss A, Corbin J. Basics of qualitative research: Techniques and procedures for developing grounded theory. Thousand Oaks, CA: Sage Publications; 1998.

[12] Anthony AS. Gender bias and discrimination in nursing education: Can we change it? Nurs Educ. 2004 May-Jun; 29(3): 121-125. PMid:15167580. http://dx.doi.org/10.1097/00006223-200 405000-00011

[13] O'Lynn CE. Gender-based barriers for male students in nursing education programs: Prevalence and perceived importance. J Nurs Educ. 2004 May; 43(5): 229-236. PMid:15152800. 